Original article

\title{
EFFECTS OF BUTYLATED HYDROXYTOLUENE ON BLOOD LIVER ENZYMES AND LIVER GLUTATHIONE AND GLUTATHIONE-DEPENDENT ENZYMES IN RATS
}

\author{
S. MEAN $^{1}$, Y. DEĞER ${ }^{2} \&$ S. YILDIRIM ${ }^{3}$ \\ ${ }^{1}$ District and Research Hospital of Van, Brain Research Service, Van, Turkey; \\ ${ }^{2}$ Department of Biochemistry, Faculty of Veterinary Medicine, Yüzüncü Yıl University, \\ Van, Turkey; ${ }^{3}$ Department of Pathology, Faculty of Veterinary Medicine, \\ Atatürk University, Erzurum, Turkey
}

\section{Summary}

Mean, S., Y. Değer \& S. Yildirim, 2018. Effects of butylated hydroxytoluene on blood liver enzymes and liver glutathione and glutathione-dependent enzymes in rats. Bulg. J. Vet. Med., 21, No 4, 461-469.

This study was aimed to detect the effect of butylated hydroxytoluene (BHT) on the liver glutathione level and glutathione-dependent enzyme activities in female Wistar albino rats. BHT was administered by oral gavage at a dose of $250 \mathrm{mg} / \mathrm{kg}$ (Group I) and $500 \mathrm{mg} / \mathrm{kg}$ (Group II) for 28 days, 1000 $\mathrm{mg} / \mathrm{kg}$ (Group III) and $1500 \mathrm{mg} / \mathrm{kg}$ (Group IV) for 4 days. The serum ALT, AST and LDH activities were measured on an autoanalyzer, and liver gluthathione (GSH), gluthathione peroxidase (GPx), gluthathione S-transferase (GST), and gluthathione reductase (GR) activities were analysed with commercial ELISA kits. The ALT activity was significantly higher in Groups III and IV $(\mathrm{P}<0.05$ and $\mathrm{P}<0.001$, respectively) compared to the control group. Blood AST and LDH activities were significantly increased in Group IV $(\mathrm{P}<0.05)$. The GSH, GPx, GST and GR in the liver tissue were determined to be statistically low in Groups II, III and IV $(\mathrm{P}<0.001)$ in comparison with control group. In microscopic examination, BHT caused histopathological changes in the rat liver tissue in Groups II, III and IV depending on the dose and duration of exposure. It can be concluded that BHT plays a role in producing liver damage in rats with depressed hepatic antioxidant defense. The hepatotoxic response seemed to be dose- and time-dependent.

Key words: antioxidant enzymes, butylated hydroxytoluene, glutathione, histopathology, liver

\section{INTRODUCTION}

Butylated hydroxytoluene (2,6-di-tertbutyl-p-kresol or 2,6-di-tert-butyl-4-methyl phenol; BHT) is a synthetically prepared phenolic antioxidant, which is mainly used in food containing solid and liquid fat, packing material and cosmetic products. Fat and fat-containing foods are susceptible to fermentation and other oxidation reactions. BHT acts as radical scavenger against lipid oxidation resulting of 
free radical chain reaction and thereby protects foods from deterioration (Lanigan \& Yamarik, 2002). BHT is generally recognised as a safe food additive (E 321). The Joint Expert Committee on Food Additives of the FAO/WHO approved an acceptable daily intake for man of $0.5 \mathrm{mg} \mathrm{BHT} / \mathrm{kg}$ body weight. It is rapidly absorbed from the gastrointestinal tract and distributed to liver and body fat (Panicker et al., 2014).

BHT is primarily metabolised in the liver microsomes. Rat liver BHT is metabolised to a variety of sulfate and glucuronic acid conjugates eventually excreted in the urine and faeces and to some extent through bile (Panicker et al., 2014). Cytochrome P450 mediated metabolism in liver causes the formation of a reactive and electrophilic metabolite BHT quinone methide (BHT-QM; 2,6-di-tert- butyl4methylenecyclohexa- 2,5-dienone), an intermediate metabolite of BHT which can covalently bind to various cellular nucleophiles, especially those containing sulfhydryl groups such as cysteine and glutathione which consequently leads to acute hepatotoxicity (Devi et al., 2003). Some investigations on the mechanism of BHT-induced plasma transaminase activity were used to indicate toxicity (Nakagawa, 1987).

The endogenous glutathione (GSH), synthesised mainly in the liver, plays an important role in the cell defense system. GSH, being a thiol compound, acts in cells as an antioxidant. GSH, as a cofactor of glutathione peroxidase (GPx), participates in the reduction of peroxides with concomitant formation of oxidised glutathione disulfide (GSSG). At normal physiological conditions GSSG is reduced to GSH by glutathione reductase (GR) at the expense of reduced nicotinamide adenine dinucleotide phosphate (NADPH), thereby forming a redox cycle (Parke \& Piotrowski, 1996). The glutathione peroxidase/glutathione reductase redox cycle is responsible for the maintenance of proper GSH concentration (Dringer, 2000). GSH is also involved in detoxication of many xenobiotics through the formation of S-conjugates with toxic metabolites in the second phase of biotransformation. GSH forms S-conjugates also with products of lipid peroxidation. The reaction of S-conjugation can be significantly accelerated by glutathione Stransferase (GST) (Jurczuk et al., 2006).

Butylated hydroxytoluene has been subjected to extensive toxicological studies in various animals. The $\mathrm{LD}_{50}$ value of BHT in rats when administered orally is $>2930 \mathrm{mg} / \mathrm{kg}$. At high doses it is known to cause haemorrhagic death because of the inhibition of hepatic prothrombin synthesis. BHT has been shown to induce reversible mixed function oxidases and liver enlargement in rats and peliosis, hepatocellular vacuolation, degeneration and necrosis in the liver of mice and found to increase the mitotic activity of liver cells in rats (Devi et al., 2003).

BHT is used to treat herpes in humans and is found to be effective against a wide variety of lipid coated viruses like Newcastle disease virus. BHT can act both as promoter and antipromotor of carcinogenesis (Panicker et al., 2014). Despite the antioxidant and antiviral effects, many questions about the use of BHT remain unanswered. Therefore, the present study was carried out to evaluate the toxic effects of BHT in rat liver.

\section{MATERIALS AND METHODS}

\section{Animals}

Fourty seven female Wistar Albino rats (200-250 g on average) were used in the 
study. They were housed in the cages on a $12 \mathrm{~h}$ light-dark cycle at $22 \pm 2{ }^{\circ} \mathrm{C}$. They were maintained on food pellets and drinking water ad libitum. The study was approved by the Animal Use Ethics Commision (31.03.2014) of Yüzüncü Y1l Universty.

\section{Experimental design}

The rats were randomly divided into five groups as control $(n=7)$ and BHT groups $(n=10)$. The rats in the control group were given only corn oil.

BHT (Sigma-B1378, E321) was dissolved in corn oil and administered by oral gavage to the different treatment groups as followed: Group I $(250 \mathrm{mg} / \mathrm{kg}$ for 28 days), Group II (500 mg/kg for 28 days), Group III (1000 mg/kg for 4 days) and Group IV (1500 mg/kg for 4 days) (Powell et al.,1986).

\section{Sample collection and analysis}

At the end of the trial period, intraperitoneal $75 \mathrm{mg} / \mathrm{kg}$ ketamine HCI was injected, and the blood was collected by heart puncture. Then, the collected blood was centrifuged at $+4{ }^{\circ} \mathrm{C}, 3000 \mathrm{rpm}$ for 5 min to obtain serum. ALT, AST and LDH activities in the extracted serum were measured on an autoanalyser (Roche/Hitachi) using commercial kits.

The rats were immediately sacrificed by bloodless method under ketamine anaesthesia, and the liver was excised. Samples of liver tissue were homogenised in cold $0.1 \mathrm{mM}$ phosphate buffer $(\mathrm{pH}$ 7.4), and centrifuged at $10,000 \mathrm{rpm}$ at $4{ }^{\circ} \mathrm{C}$ for $15 \mathrm{~min}$. The GSH level and GPx, GR, GST activities in the collected supernatants were measured by ELISA (Zenyth $200 \mathrm{rt}$ ) using commercial kits (Cayman Chemical Company, Ann Arbor, MI, 2014).

\section{Histopathogical analysis}

For histopathological evaluation, the liver tissue samples were fixed in $10 \%$ formalin solution for $48 \mathrm{~h}$, and then washed in tap water for $8 \mathrm{~h}$. During the routine tissue control stage, they were treated with alcohol $\left(70^{\circ}, 80^{\circ}, 90^{\circ}, 96^{\circ}, 100^{\circ}\right)$ and xylene, embedded in paraffin. Slides of $4 \mu \mathrm{m}$ thickness were cut from each block, stained with haematoxylin-eosin (H\&E), investigated under light microscope and the relevant areas were photographed (Luna, 1968; Taylor \& Cote, 1994).

\section{Statistical analysis}

The Kolmogorov-Smirnov test was used to analyse the normal distribution of continuous data. For the variables showing normal distribution, one way analysis of variation (one-way ANOVA) was used for the comparison of the groups. The level of significance was set up to $\mathrm{P}<0.05$, $\mathrm{P}<0.001$. All data were analysed by using SPSS 20.0 software.

\section{RESULTS}

\section{Biochemical results}

Blood ALT activity was significantly increased in in Groups III and IV $(\mathrm{P}<0.05$ and $\mathrm{P}<0.001$, respectively) with regard to the control group, while no statistically significant change was observed between the other two groups and the control group. The AST and LDH activities were found to be significantly increased in Group IV $(\mathrm{P}<0.05)$ compared to all other groups (Table 1). The liver tissue GSH level and GPx, GST, GR activities were significantly decreased in Groups II, III and IV when compared to the control group $(\mathrm{P}<0.001)$, and no significant difference was detected between Group I and the control group (Table 2). 
Effects of butylated hydroxytoluene on blood liver enzymes and liver glutathione and ....

Table 1. Effect of butylated hydroxytoluene on the activities of ALT, AST and LDH in rat serum. Values are presented as mean $\pm \mathrm{SD}$ ( $\mathrm{n}=7$ for controls, $\mathrm{n}=10$ for all treatment groups)

\begin{tabular}{llll}
\hline Groups & ALT (U/L) & AST (U/L) & LDH (U/L) \\
\hline Control & $36.62 \pm 2.10^{\mathrm{a}}$ & $126.18 \pm 13.79^{\mathrm{a}}$ & $1041.57 \pm 150.48^{\mathrm{a}}$ \\
Group I & $39.12 \pm 2.14^{\mathrm{a}}$ & $160.55 \pm 12.24^{\mathrm{ab}}$ & $1156.57 \pm 185.79^{\mathrm{ab}}$ \\
$250 \mathrm{mg} / \mathrm{kg} ; 28$ days & & $176.95 \pm 19.49^{\mathrm{ab}}$ & $1212.28 \pm 107.87^{\mathrm{ab}}$ \\
Group II & $61.47 \pm 6.70^{\mathrm{ab}}$ & $218.20 \pm 11.80^{\mathrm{ab}}$ & $1221.00 \pm 220.09^{\mathrm{ab}}$ \\
$\begin{array}{l}500 \mathrm{mg} / \mathrm{kg} ; 28 \text { days } \\
\text { Group III }\end{array}$ & $82.62 \pm 3.77^{\mathrm{bc}}$ & $306.24 \pm 90.74^{\mathrm{b}^{*}}$ & $2280.85 \pm 543.78^{\mathrm{b}^{*}}$ \\
$\begin{array}{l}1000 \mathrm{mg} / \mathrm{kg} ; 4 \text { days } \\
\text { Group IV }\end{array}$ & $98.51 \pm 13.84^{\mathrm{c}^{* *}}$ & & \\
\hline 1500 mg/kg; 4 days & & &
\end{tabular}

The difference among the group averages with different letters in the same column is statistically significant, $* \mathrm{P}<0.05, * * \mathrm{P}<0.001$.

Table 2. Effect of butylated hydroxytoluene on the level of rat liver gluthathione (GSH), gluthathione peroxidase (GPx), gluthathione S-transferase (GST), and gluthathione reductase (GR). Values are presented as mean $\pm \mathrm{SD}$ ( $\mathrm{n}=7$ for controls, $\mathrm{n}=10$ for all treatment groups)

\begin{tabular}{lcccc}
\hline Groups & $\begin{array}{c}\text { GSH } \\
(\mathrm{nmol} / \mathrm{min} / \mathrm{mg})\end{array}$ & $\begin{array}{c}\text { GPx } \\
(\mathrm{nmol} / \mathrm{min} / \mathrm{mg})\end{array}$ & $\begin{array}{c}\text { GST } \\
(\mathrm{nmol} / \mathrm{min} / \mathrm{mg})\end{array}$ & $\begin{array}{c}\mathrm{GR} \\
(\mathrm{nmol} / \mathrm{min} / \mathrm{mg})\end{array}$ \\
\hline Control & $4.43 \pm 0.04^{\mathrm{a}}$ & $210.00 \pm 3.40^{\mathrm{a}}$ & $289.85 \pm 2.63^{\mathrm{a}}$ & $198.00 \pm 1.91^{\mathrm{a}}$ \\
$\begin{array}{l}\text { Group I } \\
250 \mathrm{mg} / \mathrm{kg} ; 28 \text { days }\end{array}$ & $4.27 \pm 0.03^{\mathrm{a}}$ & $202.71 \pm 1.86^{\mathrm{ab}}$ & $273.71 \pm 6.78^{\mathrm{ab}}$ & $190.42 \pm 2.51^{\mathrm{a}}$ \\
$\begin{array}{l}\text { Group II } \\
500 \mathrm{mg} / \mathrm{kg} ; 28 \text { days }\end{array}$ & $1.72 \pm 0.06^{\mathrm{b}^{* *}}$ & $193.85 \pm 2.14^{\mathrm{b}^{* *}}$ & $260.85 \pm 6.13^{\mathrm{b}^{* *}}$ & $178.14 \pm 1.95^{\mathrm{b}^{* *}}$ \\
$\begin{array}{l}\text { Group III } \\
1000 \mathrm{mg} / \mathrm{kg} ; 4 \text { days }\end{array}$ & $1.01 \pm 0.05^{\mathrm{c}^{* *}}$ & $159.28 \pm 1.12^{\mathrm{c}^{* *}}$ & $197.57 \pm 4.05^{\mathrm{c}^{* *}}$ & $173.14 \pm 1.69^{\mathrm{b}^{* *}}$ \\
$\begin{array}{l}\text { Group IV } \\
1500 \mathrm{mg} / \mathrm{kg} \text {; 4 days }\end{array}$ & $0.45 \pm 0.01^{\mathrm{d}^{* *}}$ & $81.57 \pm 2.47^{\mathrm{d}^{* *}}$ & $143.00 \pm 6.06^{\mathrm{d}^{* *}}$ & $130.71 \pm 1.92^{\mathrm{c}^{* *}}$ \\
\hline
\end{tabular}

The difference among the group averages with different letters in the same column is statistically significant, $* \mathrm{P}<0.05, * * \mathrm{P}<0.001$.

\section{Histopathological results}

The liver tissue was normal in the control group (Fig. 1A) and Group I (Fig. 1B); hepatic congestion and mild degeneration were detected in central hepatocytes in Group II (Fig. 1C); congestion, degeneration, many necrotic fields and haemorrhagic foci in central hepatocytes were observed in Group III (Fig. 1D). Around the necrotic foci and in the portal region in Group IV (Fig. 1E,F), many necrotic, haemorrhagic fields in the central region and lympho-plasmocytic cell infiltration were detected. Although the histopathological findings in the Groups III and IV were similar, necrotic haemorrhagic changes in Group IV were more severe. 

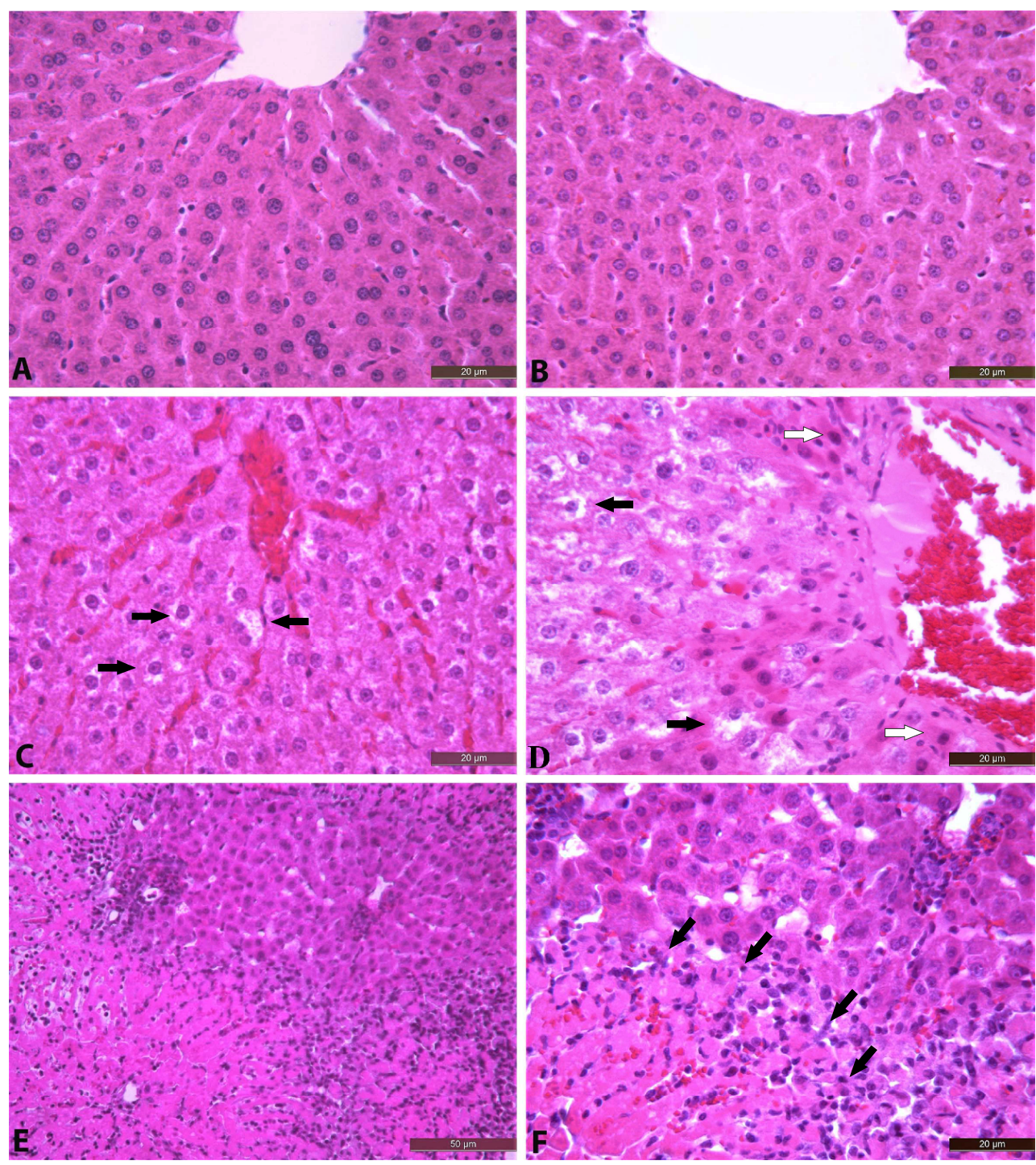

Fig. 1. Histopathological structure of the liver tissue of rats (H\&E staining). A. Control group (bar: $20 \mu \mathrm{m})$. B. Group I. The liver tissue structure is normal (bar: $20 \mu \mathrm{m})$. C. Group II. Hepatic congestion in the liver tissue and degeneration in the hepatocytes (bar: $20 \mu \mathrm{m}$ ). D. Group III. Congestion in the liver tissue, degeneration in the hepatocytes (black arrows), a number of necrotic areas and haemorrhagic foci (white arrows), (bar: $20 \mu \mathrm{m}$ ). E. Group IV. Severe necrotic, haemorrhagic areas in the liver tissue and lymphocytic cell infiltration around these necrotic foci and in the portal area (bar: $50 \mu \mathrm{m})$. F. Group IV. Severe necrotic, haemorrhagic areas in the liver tissue (bar: $20 \mu \mathrm{m}$ ). 
Effects of butylated hydroxytoluene on blood liver enzymes and liver glutathione and ....

\section{DISCUSSION}

Toxicological studies with BHT supplementation to animal feed found that adverse effects were dose-dependent. BHT amounts in excess of $526 \mathrm{mg} / \mathrm{kg} /$ day resulted in pleural and peritoneal haemorrhage in laboratory rats (Takahashi \& Hiraga, 1978) A human consumes approximately $0.1 \mathrm{mg} / \mathrm{kg} /$ day of BHT. Research shows that 500 times $(50 \mathrm{mg} / \mathrm{kg} /$ day $)$ this amount yields no deleterious effects (Branen, 1975).

AST, ALT and LDH are intra-cellular enzymes that play a role in amino acid and carbohydrate metabolism. These enzymes are present in high concentrations in the liver, muscle and brain. During liver damage, transport functions of hepatocytes are impaired and serum enzyme activity increases due to leakage from the plasma membrane. Elevated activities of AST, ALT and LDH in the serum indicate liver necrosis or disease (Jang et al., 1999; Lin et al., 2007).

We observed that serum AST, ALT and $\mathrm{LDH}$ activities increased in all groups following BHT administration. The increase in AST, ALT and LDH activities were statistically significant in Groups III and IV. The increase in liver enzyme activities occurred in a dose dependent manner. The present findings correlate with the reports of many studies using different doses of BHT (Nakagawa et al., 1984; Nakagawa, 1987; Ip \& Ko, 1996; Devi et al., 2003; Farag et al., 2006; ElAnany \& Ali, 2013; Panicker et al., 2014). On the other hand, some studies reported that none of tested BHT doses led to difference in serum transaminase activities (Jaeschke \& Wendel, 1985; 1986; Jang et al., 1999). Yamamoto et al. (1995), also did not observe any difference in AST and ALT activities in the blood when rats were fed a diet containing $0.2 \%$ BHT.

The liver has many defense and adaptation mechanisms against oxidants and xenobiotics. It has known that GST catalyses the conjugation of the biological nucleophile GSH with many electrophilic compounds. That is to say, GSH and GST play an important role in the detoxification of xenobiotic compound containing the carcinogen (Nakagawa et al., 1981). Maintenance of mitochondrial GSH redox is of great importance in order to prevent chemical hepatic injury as the decrease in mitochondrial GSH-related protein thiols is critical for cell viability (Ip \& Ko, 1996). The activated metabolite of BHT formed by the microsomal monooxygenase system is bound to the thiol compounds (Mizutani et al., 1987; Witschi et al., 1989; Devi et al., 2003). The induction threshold of the glutathione conjugation system in liver is greater than or equal to $100 \mathrm{mg} / \mathrm{kg}$ for BHT (Jaeschke \& Wendel, 1986).

It has been reported that oral administration of $500 \mathrm{mg} / \mathrm{kg}$ of BHT (Nakagawa et al., 1981) and dietary intake of 5\% BHT (Cha \& Heine, 1982) elevated the total level of GSH and the activity of GST, but has not effect on GPx activity (Nakagawa et al., 1981). It was observed that liver GSH level was decreased and did not alter GST activity after the application of BHT (Nakagawa et al., 1984). Awasthi et al. (1983) reported that 0.4 w/w BHT feeding increased liver GST activity and did not alter GPx activity

In a study investigating the effect of adding BHT in two different rodent species, the liver GR activity increased significantly only in rats and GST activity - in both mice and rats (Jaeschke \& Wendel, 1985). Also, other studies reported that the addition of 4000 and 1000 
ppm BHT significantly enhanced GST activity of turkeys' liver (Klein et al., 2002; Coulombe et al., 2005). It was reported that $3 \mathrm{mmol} / \mathrm{kg}$ BHT application decreased liver GSH level and increased GR activity (Ip \& Ko, 1996). The liver GPx and GST activities were increased after dietary supplementation of $0.05 \%$ and $0.5 \%$ BHT (Jang et al., 1999). The liver GPx activity decreased following application of BHT at $1000 \mathrm{mg} / \mathrm{kg}$ dosage (Lin et al., 2007).

In the our study, twenty eight days after the administration of $250 \mathrm{mg} / \mathrm{kg}$ of BHT, no noteworthy change was observed in GSH level and the GPx, GST and GR activities in rat liver. The lack of agreement among various studies including our results with respect to antioxidant parameters may be likely due to differences in dosage, age, periods of experiment, even animal strain and gender (Egaas et al., 1995). However, twenty eight or four days after the administration of 500, 1000 and $1500 \mathrm{mg} / \mathrm{kg}$ of BHT the GSH level and GPx, GST, GR activities significantly decreased. The decreased liver activity of GPx due to BHT administration might result from the involvement of this enzyme in the dismutation of peroxides generated during BHT biotransformation. Because GSH is utilised in the GPxmediated reactions, an enhanced intensity of these reactions might also be a cause of decrease in GSH concentration in the liver of the BHT treated rats. In a reaction catalysed by GPx, an oxidised form of GSH: GSSG is formed. Under the influence of GR and reduced nicotinamide adenine dinucleotide phosphate (NADPH), GSSG is reduced to GSH (MoniuszkoJakoniuk et al., 2007). The decrease in liver GR activity in rats treated with BHT might result from this enzyme utilisation for GSSG reduction or from NADPH deficiency. GST catalyses reactions of toxic substances conjugation with GSH (Jurczuk et al., 2006). The decreased GST activity in the liver of rats exposed to BHT alone suggests that the reduction of GSH concentration in this organ might result from GSH utilisation in antioxidative reactions. These liver biochemical alterations were accompanied by amelioration of histopathological degenerative changes seen in liver of BHT administred rats.

Sevaral studies indicated that BHT caused liver damage (Nakagawa et al., 1981; Lanigan \& Yamarik, 2002). The hydropic degeneration (Klein et al., 2003), vacuolar degeneration and hepatocellular degeneration including fuzzy swelling (El-Anany \& Ali, 2013) and necrosis (Powell et al., 1986) were reported. Contrary to the above mentioned studies, Jang et al., (1999) and Lin et al., (2007) showed that BHT caused no histopathological changes in liver. In this study, the livers of rats in the Group I had normal appearance. The histopathological degenerative changes in liver tissue were observed as congestion, degeneration, necrosis, haemorrhages in the other BHTtreated groups. The severety of these changes increased as a function of applied dose of BHT.

As a result, it can be said that BHT plays a role in producing liver damage in rats with depressed hepatic antioxidants. The hepatotoxic response seemed to be dose- and time- dependent.

\section{ACKNOWLEDGEMENTS}

This study was supported by the Yüzüncü Y1l University Scientific Research Projects Fund and registered with project No: 2014-SBEYL137. 
Effects of butylated hydroxytoluene on blood liver enzymes and liver glutathione and ....

\section{REFERENCES}

Awasthi, Y. C., C. A. Partridge \& D. D. Dao, 1983. Effect of butylated hydroxytoluene on glutathione S-transferase and glutathione peroxidase activities in rat liver. Biochemical Pharmacology, 1, 1197-200.

Branen, A. L., 1975. Toxicology and biochemistry of butylated hyrroxyanisole and butylated hydroxytoluene. Journal of the American Oil Chemists' Society, 52, 5963.

Cha, Y. N. \& H. S. Heine, 1982. Comparative effects of dietary administration of 2(3)ferf-butyl-4- hydroxyanisole and 3,5-diferf-butyl-4-hydroxytoluene on several hepatic enzyme activities in mice and rats. Cancer Research, 42, 2609-2615.

Coulombe, R. A., J. A. Guarisco, P. J. Klein \& J. O. Hall, 2005. Chemoprevention of aflatoxicosis in poultry by dietary butylated hydroxytoluene. Animal Feed Science and Technology, 121, 217-225.

Devi, R. S., N. Shoba, M. K. Vijai, K. Sabitha, E. Shyamala \& C. S. Devi, 2003. Effect of a polyherbal formulation, Ambrex, on butylated hydroxy toluene (BHT) induced toxicity in rats. Indian Journal of Experimental Biology, 41, 1290-1294.

Dringer, A., 2000. Metabolism and function of glutathione in brain. Progress in Neurobiology, 62, 649-671.

Egaas, E., F. G. Falls \& W. C. Dauterman, 1995. A study of gender, strain and age differences in mouse liver glutathione-Stransferase. Comparative Biochemistry and Physiology Part C: Pharmacology, Toxicology and Endocrinology, 110, 35-40.

El-Anany, A. \& R. Ali, 2013. Biochemical and histopathological effects of administration various levels of Pomposia (Syzygium cumini) fruit juice as natural antioxidant on rat health. Journal of Food Science and Technology, 50, 487-495.

Farag, R. S., E. A. Mahmoud, A. M. Basuny \& R. F. Ali, 2006. Influence of crude olive leaf juice on rat liver and kidney functions.
International Journal of Food Science and Technology, 41, 790-798.

Ip, S. P. \& K. M. Ko, 1996. The crucial antioxidant action of schisandrin $\mathrm{B}$ in protecting against carbon tetrachloride hepatotoxicity in mice: A comparative study with butylated hydroxytoluene. Biochemical Pharmacology, 52, 1687-1693.

Jaeschke, H. \& A. Wendel, 1985. Manipulation of mouse organ glutathione contents I: Enhancement by oral administration of butylated hydroxyanisole and butylated $h y$ droxytoluene. Toxicology, 36, 77-85.

Jaeschke, H. \& A. Wendel, 1986. Manipulation of mouse organ glutathione contents. II: Time and dose-dependent induction of the glutathione conjugation system by phenolic antioxidants. Toxicology, 39, 59-70.

Jang, I. S., K. R. Chae, T. S. Kang, Y. K. Kim, C. K. Kim, J. H. Hwang, D. Y. Hwang, C. B. Choi, K. K. Jung \& J. S. Cho, 1999. Effects of long-term vitamin $\mathrm{E}$ and butylated hydroxytoluene supplemented diets on murine intestinal and hepatic antioxidant enzyme activities. AsianAustralasian Journal of Animal Sciences, 12, 932-938.

Jurczuk, M., J. Moniuszko-Jakoniuk \& J. Rogalska, 2006. Glutathione-related enzyme activity in liver and kidney of rats exposed to cadmium and ethanol. Polish Journal of Environmental Studies, 15, 861-868.

Klein, P. J., T. R.Van Vleet, J. O. Hall \& R. A. Coulombe Jr, 2002. Dietary butylated hydroxytoluene protects against aflatoxicosis in turkeys. Toxicology and Applied Pharmacology, 182, 11-19.

Klein, P. J., T. R. Van Vleet, J. O. Hall \& R. A. Coulombe Jr., 2003. Effects of dietary butylated hydroxytoluene on aflatoxin B1relevant metabolic enzymes in turkeys. Food and Chemical Toxicology, 41, 671678.

Lanigan, R. S \& T. A. Yamarik, 2002. Final report on the safety assessment of BHT(1). 
International Journal of Toxicology, 21, 19-94.

Lin, H. M., F. L. Yen, L. T. Ng \& C. C. Lin, 2007. Protective effects of Ligustrum lucidum fruit extract on acute butylated hydroxytoluene-induced oxidative stress in rats. Journal of Ethnopharmacology, 111, 129-136.

Luna, L. G., 1968. Manual of Histologic Staining Methods of the Armed Forces Institute of Pathology. $3^{\text {rd }}$ edn, McGraw-Hill, New York, NY.

Mizutani, T., H. Nomura, K. Nakanishi \& S. Fujita, 1987. Hepatotoxicity of butylated hydroxytoluene and its analogs in mice depleted of hepatic glutathione. Toxicology and Applied Pharmacology, 87, 166176.

Moniuszko-Jakoniuk, J., J. Maria \& M. M. Brzóska, 2007. Evaluation of glutathionerelated enzyme activities in the liver and kidney of rats exposed to lead and ethanol. Pharmacological Reports, 59, 217-225.

Nakagawa, Y., K. Hiraga \& T. Suga, 1981. Effects of butylated hydroxytoluene (BHT) on the level of glutathione and the activity of glutathione-S-transferase in rat liver. Journal of Pharmacobiodynamics, 4, 823826.

Nakagawa, Y., K. Tayama, T. Nakao \& K. Hiraga, 1984. On the mechanism of butylated hydroxytoluene- induced hepatic toxicity in rats. Biochemical Pharmacology, 33, 2669-2674.

Nakagawa, Y., 1987. Effects of buthionine sulfoximine and cysteine on the hepatotoxicity of butylated hydroxytoluene in rats. Toxicology Letters, 37, 251-256.

Panicker, V. P., S. George \& B. Dhanush Krishna, 2014. Toxicity study of butylated hydroxyl toluene (BHT) in rats. World Journal of Pharmacy and Pharmaceutical Sciences, 8, 758-763.

Parke D. V. \& J. Piotrowski, 1996. Glutathione: Its role in detoxication of reactive oxygen and environmental chemicals. Acta Pharmacologica et Toxicologica, 4, 1-14.

Powell, C. J., J. C. Connelly, S. M. Jones, P. Grasso \& J. W. Bridges, 1986. Hepatic responses to the administration of high doses of BHT to the rat: their relevance to hepatocarcinogenicity. Food Chemistry Toxicology, 24, 1131-1143.

Takahashi, O. \& K. Hiraga, 1978. Doseresponse study of hemorrhagic death by dietary butylated hydroxytoluene (BHT) in male rats. Toxicology and Applied Pharmacology, 43, 399-406.

Taylor, C. R. \& R. J. Cote, 1994. Immunomicroscopy: A diagnostic tool or the surgical pathologist, $2^{\text {nd }}$ ed, Saunders Company, Philadelphia, USA.

Witschi, H., A. M. Malkinson \& J. A. Thompson, 1989. Metabolism and pulmonary toxicity of butylated hydroxytoluene (BHT). Pharmacology \& Therapeuitics, 42, 89-113.

Yamamoto, K., N. Fukuda, S. Shiroi, Y. Shiotsuki, Y. Nagata, T. Tani \& T. Sakai, 1995. Effect of dietary antioxidants on the susceptibility to hepatic microsomal lipid peroxidation in the rats. Annals of Nutrition \& Metabolism, 39, 99-106.

Paper received 03.01.2017; accepted for publication 07.04.2017

\section{Correspondence:}

Sinan Mean

District and Research Hospital of Van,

Brain Research Service,

Van, Turkey

e-mail: sinanmean@hotmail.com 